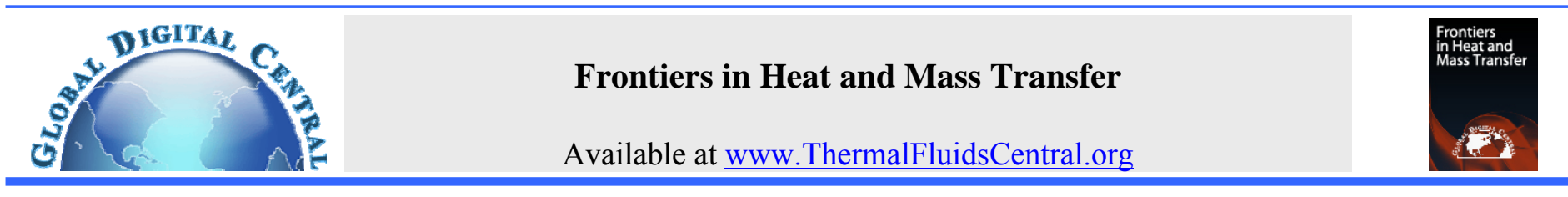

\title{
MHD MIXED CONVECTION AND ENTROPY GENERATION IN A 3D LID-DRIVEN CAVITY
}

\author{
Lioua Kolsi ${ }^{\mathrm{a}, \mathrm{b}^{*}}$ \\ ${ }^{a}$ College of Engineering , Mechanical Engineering Department , Haïl University, Haïl City, Saudi Arabia \\ ${ }^{b}$ Unité de recherche de Métrologie et des Systèmes Energétiques, Ecole Nationale d'Ingénieurs, 5000 Monastir, University of Monastir, Tunisia
}

\begin{abstract}
In this study, the effects of Richardson and Hartmann numbers on heat and mass transfer in a three-dimensional lid-driven cubical cavity subjected to a uniform magnetic field are investigated numerically. The lid is maintained at constant high temperature and is moving downwards in the negative $y$-direction. The wall opposite to the lid is stationary and maintained at constant low temperature, and all other walls are kept adiabatic. Entropy generation is also calculated to investigate the nature of irreversibility in heat transfer inside the cavity. The computations are performed for the Richardson numbers 10 and 100, and Hartmann number in the range between 0 and 80 . Prandtl number and the irreversibility coefficient are considered constant and given the values 0.054 and $10^{-4}$, respectively. It was found out that the average Nusselt number decreases when the Hartmann number increases for all values of the Richardson number. Also, the Bejan and average Nusselt numbers have a converse relationship for the same range of Hartmann and Richardson numbers. In addition, the study shows that for all the considered cases, the entropy generation rate decreases with increasing the Hartmann number.
\end{abstract}

Keywords: Magneto-hydrodynamic, Lid-driven cavity, Three-dimensional flow, Entropy generation

\section{INTRODUCTION}

Mixed convection flow and heat transfer in lid-driven cavities can be observed in many natural and industrial applications, such as lake dynamics, lubrication, drying, food processing, float glass production, solar ponds, and nuclear reactors.

Analysis of mixed convection flows requires an estimation of the relative importance of the two modes of convection, i.e. natural and forced convection. If the fluid in a mixed convection flow is electrically conducting and if the cavity is exposed to a magnetic field then the magnetic force effect on the flow has to be taken into consideration.

Some examples of electrically conducting fluids in a mixed convection flow include geothermal reservoirs, thermal insulations and petroleum reservoirs. These types of problems also arise in microelectronic devices during their operation (Nasrin (2010)). Many researchers have studied the magneto-hydrodynamic (MHD) mixed convection flows in lid-driven cavities under various boundary conditions using two-dimensional analysis. Chamkha (2002) numerically investigated unsteady, laminar, mixed convection flow in a square, isothermally heated lid-driven enclosure with heat generation and exposed to a magnetic field. He shows that the flow behavior and the heat transfer characteristics inside the enclosure were strongly affected by the magnetic field. Rahman et al. (2009), studied numerically, MHD mixed convection in a rectangular cavity with a heat conducting horizontal circular cylinder with joule heating. They found strong dependency of flow and temperature distribution on the magnetic field. Rahman et al. (2010) investigated, numerically, the conjugate effect of joule heating on MHD mixed convection in an obstructed liddriven square cavity. They concluded that the heat transfer rate decreased with decreasing Hartmann number. Rahman et al. (2010) investigated the effect of Reynolds and Prandtl numbers on MHD mixed convection in a lid-driven cavity along with joule heating and a centered heat-conducting rod. They found that Prandtl number has a greater effect on heat transfer and temperature distribution than it has on the fluid flow. Oztop et al. (2011) used the finite volume method to study the laminar mixed convection flow in the presence of magnetic field in a lid-driven cavity heated from the corners. The corner heaters were under isothermal boundary conditions with different lengths. The study was performed for different Grashof and Hartmann numbers at Reynolds number $(R e=100)$. They observed that heat transfer decreases with increasing Hartmann number and the rate of reduction was higher at higher values of the Grashof number. Rahman et al. (2011) studied numerically, using finite element method, the magnetic field and joule heating effects on the flow and thermal fields in a liddriven cavity with a centered heat-conducting block. It was found that the flow field and temperature distribution are strongly affected by the intensity of the magnetic field and joule heating, and the size of the inner block. Sivasankaran et al. (2011) studied numerically, using finite volume method, the hydro-magnetic mixed convection in a square cavity of sinusoidal temperature boundary conditions. They found that the flow inside the cavity was strongly affected by the presence of the magnetic field. When forced convection dominated, increasing Hartmann number did not affect the heat transfer on the active walls. When natural convection dominated, increasing the Hartmann number decreased the total heat transfer rate. Nasrin and Parvin (2011) investigated numerically the mixed convection flow and heat transfer in a lid-driven cavity with sine-wave shaped bottom surface under the influence of a transverse magnetic field. They concluded that the increase in Hartmann number slowed down the flow inside the cavity.

All of the above studies were performed in two-dimensional space. A limited number of studies on MHD mixed convection flows

*Email: lioua_enim@yahoo.fr 
were done in full three-dimensional space due to the added complexity and cost of the calculations. However, three dimensional studies can capture certain characteristics of the complex flows that would have not been captured in two dimensional studies. Kolsi et al. (2011) performed three-dimensional analyses of laminar mixed convection and entropy generation in a cubic side-lid-driven cavity. The cavity was heated from one side and cooled from the other, keeping all other walls adiabatic. Richardson number was varied from 0.01 to 100 , and Prandtl number was fixed at $P r=0.71$. It was found that the direction of lid movement was an important parameter affecting entropy generation and heat and fluid flow at low values of Richardson number. At high Richardson number, however, the direction of the lid movement was found to be insignificant. A study on the effect of the radiative heat transfer on the three-dimensional double diffusive convection in a differentially heated cubic cavity was performed by Abidi et al (2011). Results show different transitions of the structure of the main flow when varying the conduction-radiation parameter and the optical thickness.

Martyushev et al (2014) studied numerically the natural convection and surface thermal radiation in a cubical cavity having heat-conducting walls heat source located at the bottom. It has been shown that the average convective Nusselt number increases as function of $R a$ and decreases as function of emissivity. Sheremet (2015) studied the same configuration (without radiation) with porous media filled cubical cavity the most important funding was the nonlinear dependence between Darcy number and heat transfer. Maatki et al (2013), (2016a) and (2016b) studied the effect of the presence of a magnetic field on the $3 \mathrm{D}$ double diffusive natural convection. It was found that the produced Lorentz force opposes buoyancy and solutal forces and decreases the heat and mass transfers and the entropy generation. Entropy generation in different 3D configurations has been studied by Aich et al (2016), Hussein et al (2016) and Kolsi et al (2016a) these studies show a proportional increase of entropy generation with Rayleigh number. Some studies were dedicated to natural convection and entropy generation in 3D cavities filled with nanofluids (Kolsi et al 2014), (2016b), (2016c) and (2016d). The addition of nanoparticles was found to increase the thermal irreversibility and to reduce the viscous one.

To the best of the authors' knowledge, there is no published research up to date that investigates the entropy generation in threedimensional MHD mixed convection in a lid-driven cavity. Therefore, this is study aims at studying the three-dimensional MHD mixed convection in a cavity with moving sidewall at different values of Hartmann and Richardson numbers.

\section{Definition of geometrical configuration and assumptions}

In the present work, MHD three-dimensional mixed convection flow inside a lid-driven cavity of square base with width $(\mathrm{l})$ and height $(\mathrm{H})$ is investigated. The geometry of the cavity is depicted in Fig. 1. The cavity is filled with an electrically conducting fluid. The wall on the left of the cavity is maintained at constant high temperature and is moving in the negative y-direction. The opposing wall is maintained at constant low temperature. The remaining walls are kept adiabatic. The flow inside the cavity is subjected to a uniform magnetic field, $B_{0} \cdot \vec{e}_{B}$, in the direction perpendicular to the differentially heated cavity walls. In order to simplify the modeling of the governing equations, the following assumptions are made:

- The flow is considered unsteady, three-dimensional, incompressible and laminar.

- The fluid physical properties are assumed constant.

- All cavity walls are considered electrically insulated.

The Richardson number is varied in the range between 10 and 100, and Hartmann number between 0 and 80 . Reynolds number is fixed at 100 , the Prandtl number at 0.054 and the irreversibility coefficient at $\varphi=10^{-4}$.

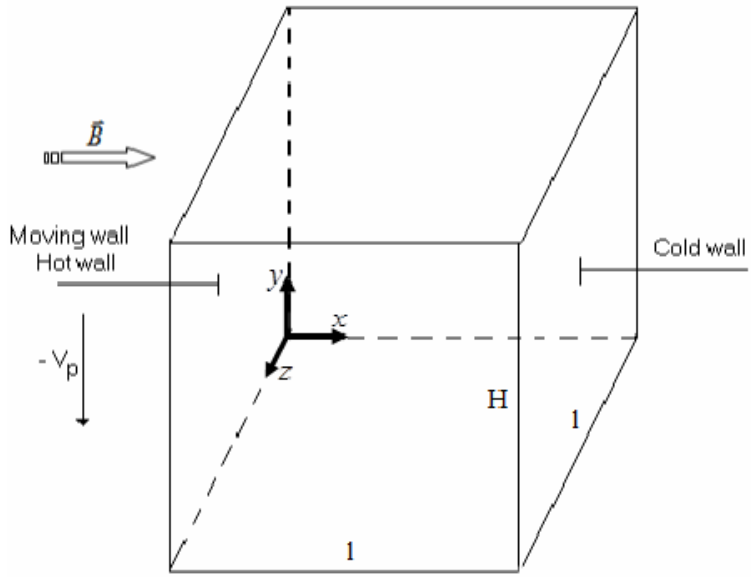

Fig. 1 Schematic diagram of the present problem.

\section{Governing equations and numerical solution}

The governing equations are presented and solved in terms of velocity potential and vorticity.

The following equations are derived following the descriptions of Kolsi et al. (2011).

The dimensionless variables used in this work are:

$(x, y, z)=\frac{\left(x^{\prime}, y^{\prime}, z^{\prime}\right)}{L}, \quad B=B^{\prime} / B_{0}, \quad \Phi=\Phi^{\prime} /\left(l \cdot v_{0} \cdot B_{0}\right), \quad J=J^{\prime} /\left(\sigma \cdot v_{0} . B_{0}\right)$,

$T=\frac{T-T_{c}}{T_{h}-T_{c}},\left(u_{x}, u_{y}, u_{z}\right)=\frac{\left(u_{x}^{\prime}, u_{y}^{\prime}, u_{z}^{\prime}\right) L}{\alpha}$ and $t=\frac{t^{\prime}}{\alpha \cdot L^{2}}$.

The governing equations can be written in a dimensionless form as follows:

$-\vec{\omega}=\nabla^{2} \vec{\psi}$

$\frac{\partial \vec{\omega}}{\partial t}+(\vec{V} . \nabla) \vec{\omega}-(\vec{\omega} . \nabla) \vec{V}=\operatorname{Pr} . \vec{\nabla}^{2} \vec{\omega}+\operatorname{Ra} \cdot \operatorname{Pr} .\left[\frac{\partial T}{\partial z} ; 0 ;-\frac{\partial T}{\partial x}\right]$ $+\operatorname{Ra} \cdot \operatorname{Pr} \cdot H a^{2} \cdot\left(\vec{\nabla} \times\left(\vec{J} \times \vec{e}_{B}\right)\right)$

$\frac{\partial T}{\partial t}+\vec{V} \cdot \nabla T=\Delta T$

$\vec{J}=-\vec{\nabla} \Phi+\vec{V} \times \vec{e}_{B}$

$\vec{\nabla}^{2} \Phi=\nabla \cdot(\vec{V} \times \vec{B})=-\vec{e}_{B} \cdot \vec{\omega}$

Where; $\quad \operatorname{Pr}=\frac{v}{\alpha}, \quad R a=\frac{g \cdot \beta \cdot \Delta T \cdot l^{3}}{v \cdot \alpha}$ and $\quad H a=\sqrt{\frac{B_{0}^{2} \cdot l^{2} \cdot \sigma}{\rho \cdot v}}$

In addition, the Richardson number is defined as:

$$
R i=\frac{G r}{\operatorname{Re}^{2}}=\frac{R a}{\operatorname{Pr} \cdot \operatorname{Re}^{2}}
$$

The control volume finite difference method is used to discretize Eqs. (1)-(3). The convective terms was treated with central-difference scheme while fully implicit procedure is utilized to discretize the temporal derivatives. The grid is uniform in all directions with additional nodes on the boundaries. The resulting non-linear algebraic equations is solved using the successive relaxation iterating scheme. The time step $\left(10^{-4}\right)$ and spatial mesh $\left(51^{3}\right)$ are used to carry out all the numerical tests. The solution is considered acceptable when the following convergence criterion is satisfied for each time step:

$\sum_{i}^{1,2,3} \frac{\max \left|\psi_{i}^{m}-\psi_{i}^{m-1}\right|}{\max \left|\psi_{i}^{m}\right|}+\max \left|T_{i}^{m}-T_{i}^{m-1}\right| \leq 10^{-5}$

Where the superscript $(\mathrm{m})$ represents the iteration number.

The boundary conditions are given as:

Temperature:

$T=1$ at $x=0, T=0$ for $x=1$ 
$\frac{\partial T}{\partial n}=0$ on all non-active walls (adiabatic condition).

Vorticity:

$$
\begin{aligned}
& \omega_{x}=0, \omega_{y}=-\frac{\partial V_{z}}{\partial x}, \omega_{z}=\frac{\partial V_{y}}{\partial x} \text { at } x=0 \text { and } 1 \\
& \omega_{x}=\frac{\partial V_{z}}{\partial y}, \omega_{y}=0, \omega_{z}=-\frac{\partial V_{x}}{\partial y} \text { at } y=0 \text { and } 1 \\
& \omega_{x}=-\frac{\partial V_{y}}{\partial z}, \omega_{y}=\frac{\partial V_{x}}{\partial z}, \omega_{z}=0 \text { at } z=0 \text { and } 1
\end{aligned}
$$

Vector potential:

$$
\begin{aligned}
& \frac{\partial \Psi_{x}}{\partial x}=\Psi_{y}=\Psi_{z}=0 \text { at } x=0 \text { and } 1 \\
& \Psi_{x}=\frac{\partial \Psi_{y}}{\partial y}=\Psi_{z}=0 \text { at } y=0 \text { and } 1 \\
& \Psi_{x}=\Psi_{y}=\frac{\partial \Psi_{z}}{\partial z}=0 \text { at } z=1
\end{aligned}
$$

Velocity:

All velocities are zero on all the walls except for the moving wall where $V_{y}=\operatorname{Re} \cdot \operatorname{Pr}$

Electrical potential:

$$
\frac{\partial \phi}{\partial n}=0 \text { (insulated walls) }
$$

Current density:

$$
\vec{J} . \vec{n}=0 \text { on all walls }
$$

where $\vec{n}$ is the unit vector normal to the wall.

Entropy generation in the presence of a magnetic field is written as,

$$
S_{\text {gen }}^{\prime}=-\frac{1}{T_{0}^{2}} \cdot \vec{q}^{\prime} \cdot \vec{\nabla} T^{\prime}+\frac{\mu}{T_{0}} \cdot \phi^{\prime}+\frac{1}{T_{0}} \cdot\left(\vec{J}^{\prime}-\rho_{e} \cdot \vec{V}^{\prime}\right) \cdot\left(\vec{E}^{\prime}+\vec{V}^{\prime} \times \vec{B}^{\prime}\right)
$$

The first term in (7) represents the entropy generation due to temperature gradient, the second is due to friction and the last is due to the magnetic field. The heat flux is calculated from the following,

$$
\vec{q}=-k \cdot g r a \vec{d} T
$$

and the dissipation function $\left(\phi^{\prime}\right)$ as (Kolsi et al. (2011)),

$$
\begin{aligned}
\phi^{\prime} & =2\left[\left(\frac{\partial V_{x}^{\prime}}{\partial x^{\prime}}\right)^{2}+\left(\frac{\partial V_{y}^{\prime}}{\partial y^{\prime}}\right)^{2}+\left(\frac{\partial V_{z}^{\prime}}{\partial z^{\prime}}\right)^{2}\right]+\left(\frac{\partial V_{y}^{\prime}}{\partial x^{\prime}}+\frac{\partial V_{x}^{\prime}}{\partial y^{\prime}}\right)^{2} \\
& +\left(\frac{\partial V_{z}^{\prime}}{\partial y^{\prime}}+\frac{\partial V_{y}^{\prime}}{\partial z^{\prime}}\right)^{2}+\left(\frac{\partial V_{x}^{\prime}}{\partial z^{\prime}}+\frac{\partial V_{z}^{\prime}}{\partial x^{\prime}}\right)^{2}
\end{aligned}
$$

(1989))

The entropy generation can then be written as (Ozoe and Okada

$S_{\text {gen }}^{\prime}=\left\{\frac{k}{T_{0}^{2}}\left[\left(\frac{\partial T^{\prime}}{\partial x^{\prime}}\right)^{2}+\left(\frac{\partial T^{\prime}}{\partial y^{\prime}}\right)^{2}+\left(\frac{\partial T^{\prime}}{\partial z^{\prime}}\right)^{2}\right]\right\}+$

$\frac{\mu}{T_{0}}\left\{\begin{array}{l}2\left[\left(\frac{\partial V_{x}^{\prime}}{\partial x^{\prime}}\right)^{2}+\left(\frac{\partial V_{y}^{\prime}}{\partial y^{\prime}}\right)^{2}+\left(\frac{\partial V_{z}^{\prime}}{\partial z^{\prime}}\right)^{2}\right]+\left(\frac{\partial V_{y}^{\prime}}{\partial x^{\prime}}+\frac{\partial V_{x}^{\prime}}{\partial y^{\prime}}\right)^{2} \\ +\left(\frac{\partial V_{z}^{\prime}}{\partial y^{\prime}}+\frac{\partial V_{y}^{\prime}}{\partial z^{\prime}}\right)^{2}+\left(\frac{\partial V_{x}^{\prime}}{\partial z^{\prime}}+\frac{\partial V_{z}^{\prime}}{\partial x^{\prime}}\right)^{2}\end{array}\right\}$

$+\frac{1}{T_{0}} \frac{1}{\sigma_{e}}\left(J_{x}^{\prime 2}+J_{y}^{\prime 2}+J_{z}^{\prime 2}\right)$

In dimensionless terms, the generated entropy number (dimensionless local entropy generation) is written as follows:

$N_{s}=S_{\text {gen }}^{\prime} \frac{1}{k}\left(\frac{I T_{0}}{\Delta T}\right)^{2}$

$$
\begin{aligned}
& N_{s}=\left[\left(\frac{\partial T}{\partial x}\right)^{2}+\left(\frac{\partial T}{\partial y}\right)^{2}+\left(\frac{\partial T}{\partial z}\right)^{2}\right] \\
& +\varphi \cdot\left\{\begin{array}{l}
{\left[\left(\frac{\partial V_{x}}{\partial x}\right)^{2}+\left(\frac{\partial V_{y}}{\partial y}\right)^{2}+\left(\frac{\partial V_{z}}{\partial z}\right)^{2}\right]} \\
+\left[\left(\frac{\partial V_{y}}{\partial x}+\frac{\partial V_{x}}{\partial y}\right)^{2}+\left(\frac{\partial V_{z}}{\partial y}+\frac{\partial V_{y}}{\partial z}\right)^{2}+\left(\frac{\partial V_{x}}{\partial z}+\frac{\partial V_{z}}{\partial x}\right)^{2}\right]
\end{array}\right\} \\
& +\varphi \cdot H a^{2}\left(J_{x}^{2}+J_{y}^{2}+J_{z}^{2}\right)
\end{aligned}
$$

where $\varphi=\frac{\mu \alpha^{2} T_{0}}{l^{2} k \Delta T^{2}}$ represents the irreversibility coefficient.

The first term in $N_{s}$ represents the local irreversibility due to temperature gradients, it is noted as $\left(N_{s-t h}\right)$. The second term represents the contribution of friction to the irreversibility and is noted as ( $\left.N_{S-f r}\right)$, while the third term represents the generated local entropy due to the Joule effect and is noted as $\left(N_{S-J}\right)$. From $\mathrm{N}_{\mathrm{s}}$ we can obtain the total dimensionless entropy generation by integrating over the whole volume of the cavity as the following:

$S_{\text {tot }}=\int_{v} N_{s} d v=\int_{v}\left(N_{s-t h}+N_{s-f r}+N_{s-J}\right) d v=S_{t h}+S_{f r}+S_{J}$

Bejan number $(\mathrm{Be})$ is the ratio of heat transfer irreversibility to the total irreversibility due to heat transfer, fluid friction and Joule effect:

$B e=\frac{S_{t h}}{S_{t h}+S_{f r}+S_{J}}$

The local and average Nusselt numbers are given by:

$\mathrm{N} u=\left.\frac{\partial T}{\partial x}\right|_{X=0,1}$ and $\mathrm{N} u_{a v}=\int_{00}^{11} \int_{0}^{1} N u d y d z$

\section{Results and Discussion}

The three-dimensional MHD mixed convection flow and heat transfer in a lid-driven cavity is investigated numerically. Mainly, the effects of Hartmann number and Richardson number on entropy generation, heat transfer, and fluid flow are investigated. Entropy generation minimization analysis is performed to obtain the thermodynamic losses inside the lid-driven cubical cavity due to heat transfer and fluid friction. The Reynolds and Prandtl numbers are considered constant at $(R e=100)$ and $(\operatorname{Pr}=0.054)$.

The solution's grid dependence is examined by means of four grid sizes. The average Nusselt number at different grid sizes is shown in Table 1. Since the difference in Nusselt number from grid sizes $51 \times$ $51 \times 51$ and $71 \times 71 \times 71$ is less than $1.3 \%$, the smaller grid size $51 \times$ $51 \times 51$ is selected for all simulations.

Table1: Grid dependency for $(R i=100$ and $H a=50)$

\begin{tabular}{|c|c|c|c|c|c|}
\hline Grid & $31 \times 31 \times 31$ & $41 \times 41 \times 41$ & $51 \times 51 \times 51$ & $61 \times 61 \times 61$ & $71 \times 71 \times 71$ \\
\hline \multirow{2}{*}{$\mathrm{Nu}_{a v}$} & 1.6963 & 1.6468 & 1.5958 & $\begin{array}{l}1.5766 \\
(1.2 \%)\end{array}$ & $\begin{array}{l}1.5750 \\
(1.3 \%)\end{array}$ \\
\hline
\end{tabular}

The validation of the present code is performed by comparing the present results with $3 \mathrm{D}$ numerical simulation of Ozoe and Okada (1989) with $P r=0.054$ and $R a=10^{6}$. The comparison shows a good agreement.

Table 2:Validation of the code with 3D numerical simulation of Ozoe and Okada (1989)

\begin{tabular}{lll}
\hline $\mathrm{Ha}$ & Author & $\mathrm{Nu} u_{a v}$ \\
\hline 100 & Present Work & 4,432 \\
\hline & Ozoe and Okada (1989) & 4,457 \\
\hline 200 & Present Work & 2,851 \\
\hline & Ozoe and Okada (1989) & 2,917 \\
\hline
\end{tabular}



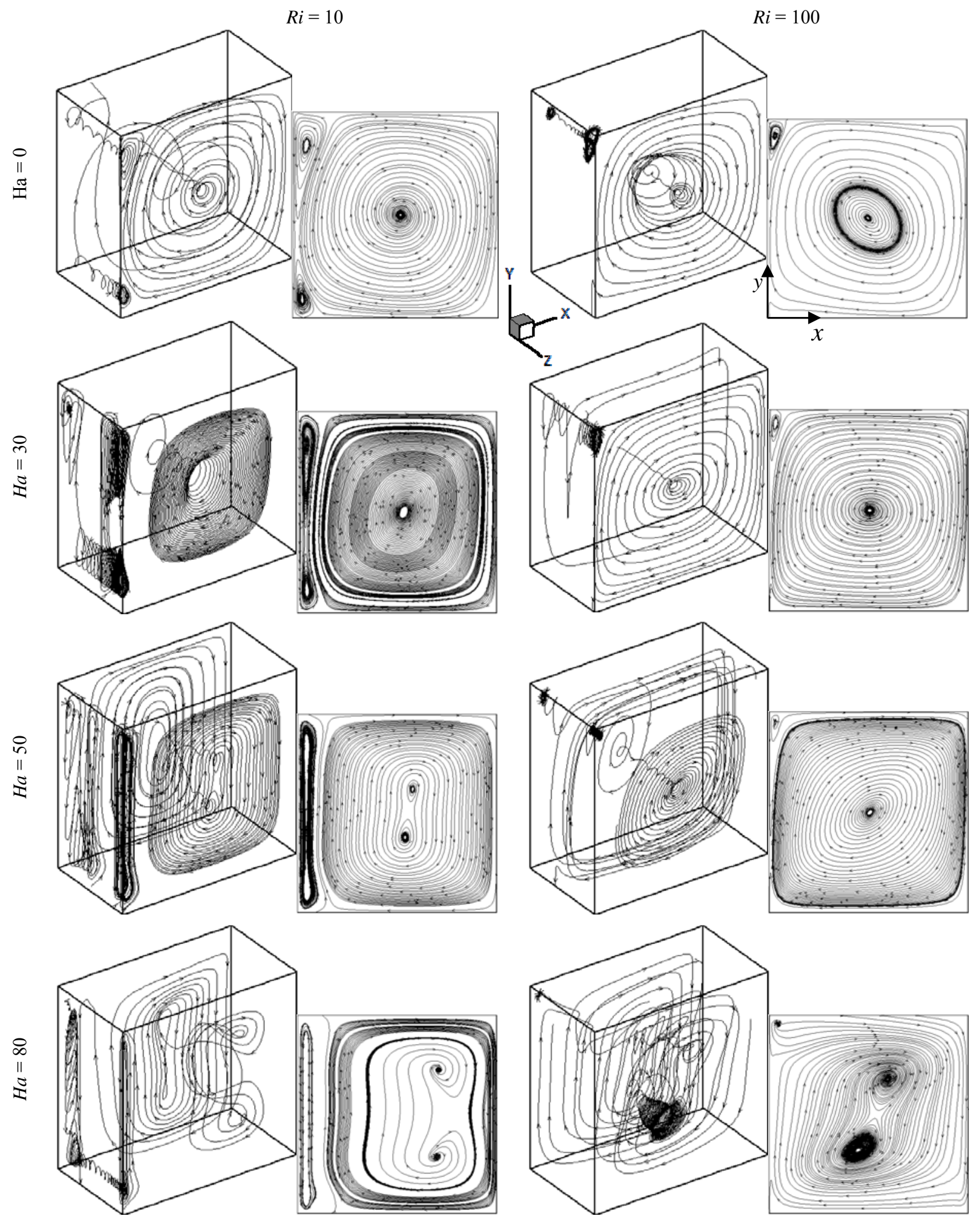

Fig. 2 Some particles trajectories for different Hartmann and Richardson numbers. 
Figure 2 shows the trajectory of particles in the cubical cavity and their projections for various values of Hartmann number $(\mathrm{Ha}=0,30$, 50 and 80) and Richardson number with the lid-driven wall moving in the negative y direction. The Hartmann number represents a measure of the relative importance of MHD induced flow. When the magnetic field effect is negligible (i.e., $\mathrm{Ha}=0$ ) and the Richardson number is low ( $R i$ $=10$ ), the main flow circulates in clockwise direction with two closed cells forming at the top and bottom corners of the moving wall. Particles are shown to spiral from the front wall to the back. These vortices are created due to shear stress from the moving wall. In this case, the effect of the Reynolds number is higher than the effect of the Rayleigh number indicating that dominance of forced convection when Richardson number is low. At high Richardson number $(R i=100)$, the core circulating vortices begins to enlarge across the diagonal of the cavity, while the minor vortices begin to diminish. In this case, the effect of Rayleigh number is higher than that of Reynolds number. In addition, increasing Hartmann number $(\mathrm{Ha}=30,50$ and 80$)$ highly affects the flow structure in the cavity's core. The flow field begins to diminish gradually until the flow becomes stationary at $H a=80$. This calming down effect on the flow field is more apparent near the moving, hot wall than the rest of the cavity. In addition, it can be seen from Fig. 2 that the circulating vortices' uniform pattern, especially in the cavity's core, begins to vanish as the Hartmann number increases. Similar observation was noted by Ozoe and Okada (1989). Furthermore, the projections of the streamlines illustrate that when the $\mathrm{Ha}=0$, the flow particles rotate outward while at $\mathrm{Ha}=80$ they rotate inward. For $H a=30$ and 50, the flow particles rotate inward in the cavity core and outward near the wall. In addition, as can be seen in Fig. 2, when $\mathrm{Ha}=30$, the three-dimensional flow inside the cavity core has a uniform spiral pattern. As the Hartmann number increases, the uniform spiral flow inside the cavity core begins to diminish while the flow near the wall is less sensitive to the magnetic field.

Fig. 3 shows the temperature iso-surfaces and isotherms pattern inside the cavity for various Hartmann and Richardson numbers. The heated fluid rises up along the hot wall and descends down the cold wall. When the effect of the magnetic field is negligible $(\mathrm{Ha}=0)$, the isotherm patterns are compressed in a non-uniform fashion indicating that the heat is transferred mainly by convection. On the contrary, when Hartmann number is high $(\mathrm{Ha}=80)$, the isotherm lines diverge and take the shape of vertical parallel lines indicating that the heat is transferred mainly by conduction. Again, this effect is due to the slowing down of the flow by the magnetic field. Also, the Richardson number has a significant influence on the temperature iso-surfaces and isotherms patterns. At low Richardson number $(R i=10)$, the isotherms are uniform and semi-symmetrical due to the weak effect of natural convection compared to the forced convection induced by the motion of the wall. But, when the Richardson number is high $(R i=100)$, the isotherms are compressed and highly non-uniform due to the strong buoyancy forces.

Fig. 4 presents the local Nusselt number variation along the hot wall (on the left) and the cold wall (on the right) in the cavity for various Hartmann and Richardson numbers. It is found that as the Hartmann number increases, the local Nusselt number at the hot and the cold walls decrease. Thus, the presence of the magnetic field decreases heat transfer rate, represented by the local Nusselt number. Also, It can be seen from Fig. 4 that the maximum local Nusselt number decreases from 2.3 at $\mathrm{Ha}=0$ to 1.06 at $\mathrm{Ha}=80$ for the hot wall and from 2.2 at $H a=0$ to 1.02 at $H a=80$ for the cold wall. These results are observed at both high and low Richardson number indicating that the pattern of the effect of the magnetic field on heat transfer inside the cavity is not affected by the motion of the wall. Fig. 5 shows the variation of the average Nusselt number in the cubical cavity for various Hartmann and Richardson numbers. It is found that the average Nusselt number decreases when the Hartmann number increases for all values of Richardson number. Also, the maximum value of the average Nusselt number occurs when the magnetic field is removed, i.e. Hartmann number is zero.
$\mathrm{Ri}=10$
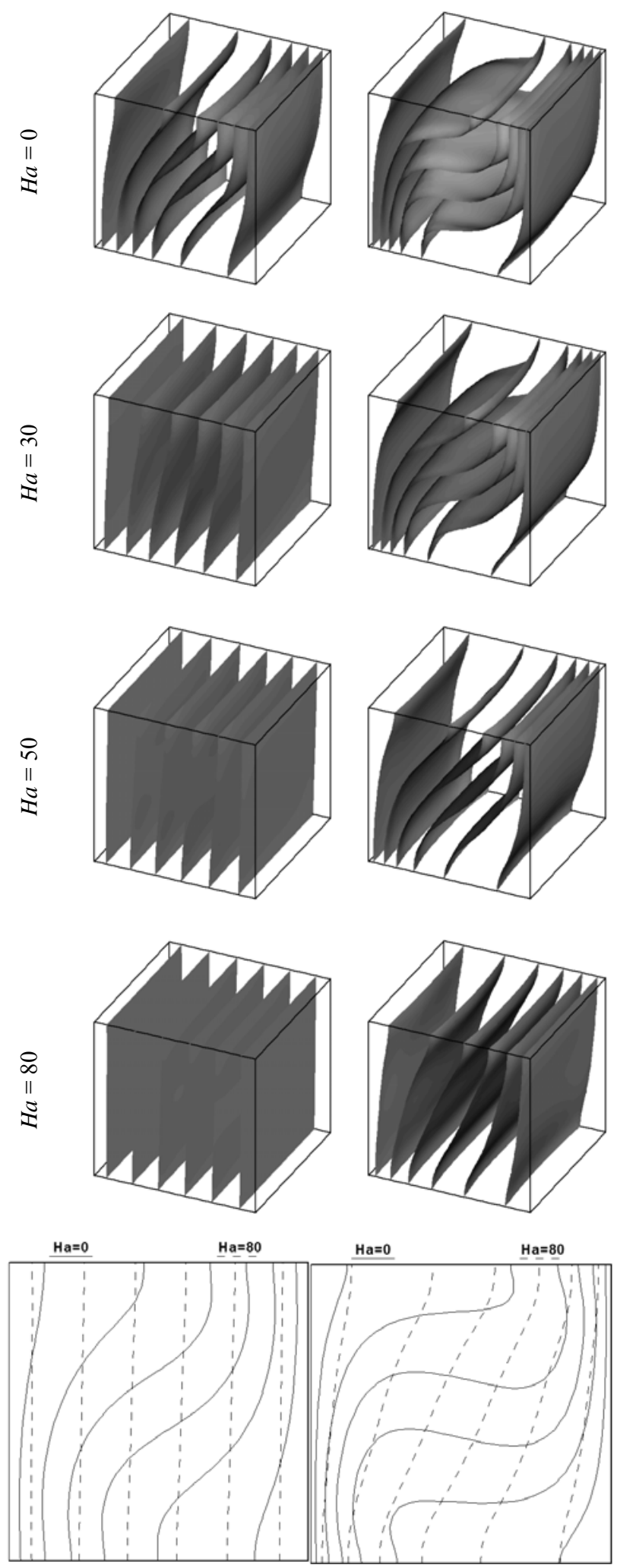

Fig. 3 Iso-surfaces of temperature and isotherms pattern in central plan for various Hartmann and Richardson numbers. 

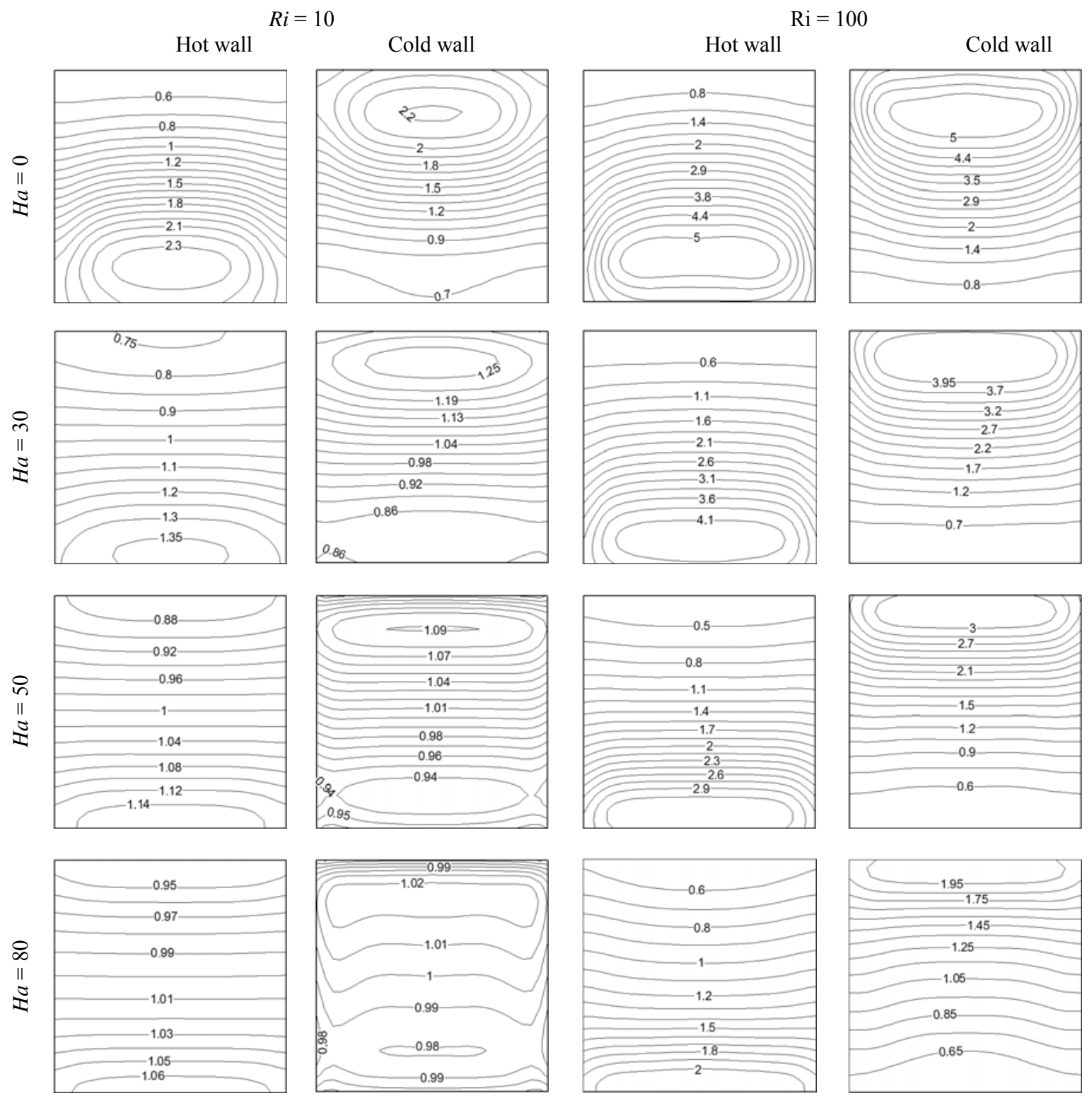

Fig. 4 Local Nusselt number along the hot wall and cold wall for various Hartmann and Richardson numbers.

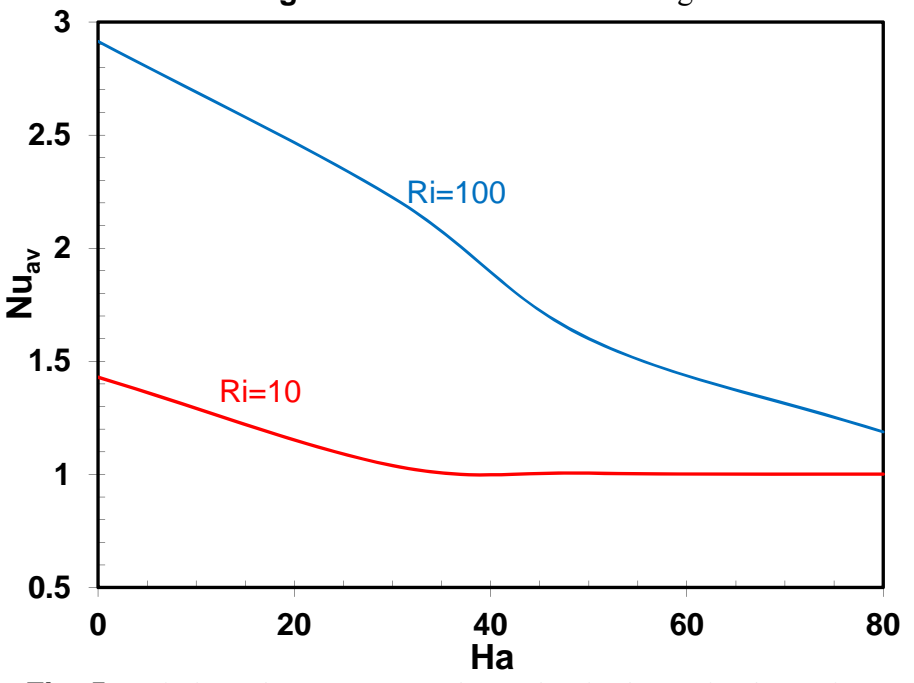

Fig. 5 Variation of average Nusselt number in the cavity for various Hartmann and Richardson numbers.
Lorentz force in the central plane of the cavity is shown in Fig. 6 for $H a=50$ and Richardson number $R i=10$ and 100 . It can be seen from the figure that the Lorentz forces' effect diminishes near the corners. This is due to the insulation condition of the walls. The insulation also caused the electric current lines to be clustered in a closed cell.

Fig. 7 shows the y-component of velocity in the plane $(y=0.5)$ for $H a=0$ and 50 and Richardson number $R i=10$ and 100 . The ycomponent of velocity decreases with increasing the Hartmann number. This is because the magnetic field reduces the flow circulation inside the cubical cavity and as a result the velocity decreases. Richarson number was found to have an opposite effect on the y-velocity, i.e. increasing Richardson number increases the flow circulation.

Fig. 8 shows entropy generation for various Hartmann and Richardson numbers. The irreversibility coefficient in the present work is taken as $\varphi=10^{-4}$. The figure shows the variation of entropy due to heat transfer, friction and Joule effect as well as the total entropy generation. The entropy contours are drawn for $\mathrm{Ha}=0$ and 50, and $\mathrm{Ri}=$ 10 and 100. It can be seen that the entropy generation decreases with increasing the Hartmann number for all the considered cases. This is due to the reduction in the heat and mass transfer with increasing the 
Hartmann number. Also, it can be observed that the entropy generation rate increases near the hot, moving wall. When Richardson number is increased, the entropy generation responds positively especially near the hot, moving wall. This is probably due to the increase in intensity of the buoyancy forces as the Richardson number is increased.

It can be observed from fig. 9 that the entropy generation rate due to heat transfer $\left(S_{t h}\right)$ and the total entropy generation $\left(\underline{S}_{\text {tot }}\right)$ have higher values when the magnetic field is at minimum, i.e. $\mathrm{Ha}=0$. It is also found that the maximum total entropy generation occurs for $\mathrm{Ha}=0$ when $R i=10$ and for $30<H a<40$ when $R i=100$. Furthermore, the entropy generation due to heat transfer $\left(S_{t h}\right)$ and the total entropy generation $\left(S_{\text {tot }}\right)$ have a similar behavior at $\mathrm{Ri}=10$ indicating the dominance of heat transfer generated entropy over the other entropy generation mechanisms. At higher Richardson number $(R i=100)$, the entropy generation due to Joule effect $\left(S_{j}\right)$ is the main contributor to the total entropy generation inside the cavity. The entropy generation due to Joule effect $\left(S_{j}\right)$ reaches a maximum value at the maximum value of Hartman number. Fig.10 shows the variation of Bejan number for various values of Hartmann number. When Bejan number is zero $(B e=$ 0 ), all irreversibilities are due to fluid friction. But, when Bejan number is equal to unity $(B e=1.0)$, all irreversibilities are due to heat transfer.

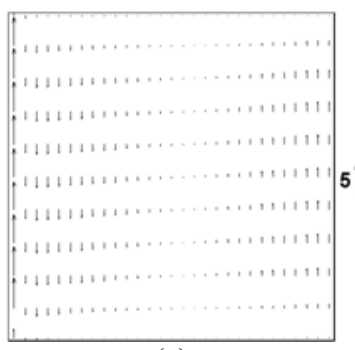

(a)

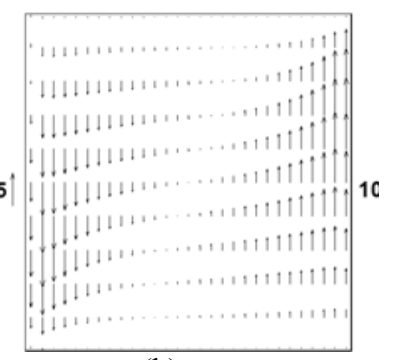

(b)
Fig. 6 The effect of the Lorentz force in the central plane of the cavity for $H a=50$; (a) $R i=10$, (b) $R i=100$
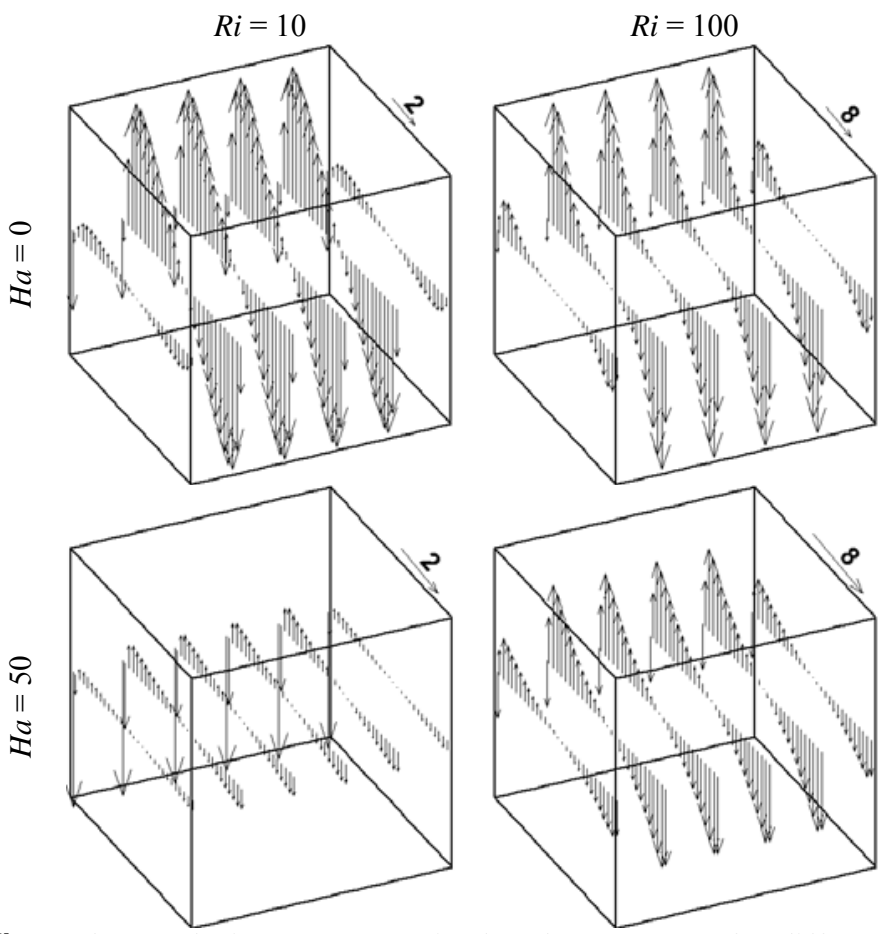

Fig.7 The y-velocity component in the plane $y=0.5$ for different Hartman and Richardson numbers.
Finally, when Bejan number is equal to one half $(B e=0.5)$, fluid friction and heat transfer contribute equally to the entropy generation. It can be seen from Fig.11 that Bejan number increases rapidly at (Ri $=10$ ). This indicates that the entropy generation rate due to the heat transfer is very significant in this range (Kolsi et al. (2011)). In addition, comparing Fig. 11 and Fig. 5 it can be seen that Bejan number and the average Nusselt number rect inversely to the changes of Hartmann and Richardson numbers. It can be seen from Fig. 11 that the Bejan number decreases with the increase of the Hartmann number for $(R i=100)$ due to the dominance of the magnetic field over the fluid motion. While a slight variation can be seen in the Bejan number when the Hartmann number increases for $(R i=10)$ due to the domination of the shear induced fluid flow in that range.

\section{Conclusions}

The main aim of this work is to present the effect of magnetic field on the fluid flow, heat transfer, and entropy generation in threedimensional lid-driven cavity. The following conclusions are drawn from observing the results of the simulations:

- $\quad$ At low Richardson number $(\mathrm{Ri}=10)$ and Hartmann number $(\mathrm{Ha}=0)$, the friction induced flow dominates the flow inside the cavity. This domination is reduced with increasing Richardson number.

- The intensity of flow circulation decreases as the Hartmann number increases and the pattern of the vortices distribution changes.

- The three-dimensional spiraling flow in the cavity core is distorted as the Hartmann number increases.

- $\quad$ At high Richardson number and low Hartmann number, heat is transfferred mainly by convection. At low Richardson number and high Hartmann number, however, heat is transferred mainly by conduction.

- The local Nusselt number at the active walls decreases when Hartmann number increases. On the contrary, increasing Richardson number increases the local Nusselt number along the active walls.

- The y-component of velocity responds negatively to the introduction of the magnetic field and positively to the increase of Richardson number.

- The entropy generation rates due to heat transfer and friction decrease with increasing the Hartmann number as a result of reduced velocities and heat transfer rate inside the cavity. The entropy generation rate due to Joule effect, however, increases sharply with the increase of Hartman number.

- Increasing Richarson number increases entropy generation.

- Bejan number decreases when the Hartmann number increases for $(R i=100)$. However, at low Richardson number $(\mathrm{Ri}=10)$, Hartman number has a weak effect on Bejan number.

\section{NOMENCLATURE}

$\mathrm{Be}$

$\mathrm{B}$ o

$\vec{e}_{B}$

Gr

$\mathrm{g}$

$\mathrm{Ha}$

$\mathrm{H}$

$\vec{J}$

$\mathrm{k}$
Bejan number

magnetic field (Tesla)

Direction of the magnetic field

Grashof number

gravitational acceleration $\left(\mathrm{m} / \mathrm{s}^{2}\right)$

Hartmann number

Cavity height (m)

Dimensionless density of electrical current

Thermal conductivity (W/ m. K)

Cavity width (m) 

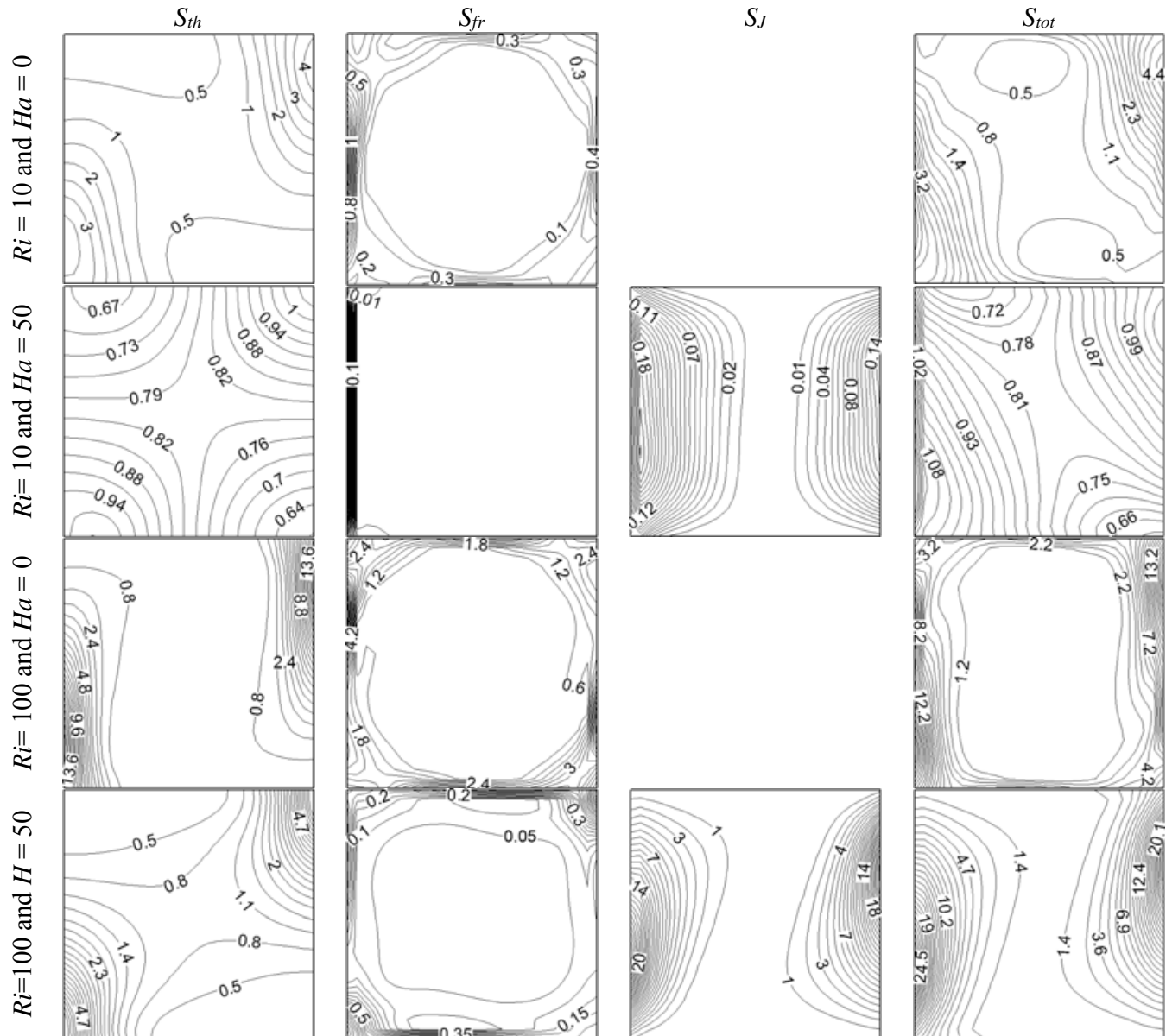

Fig.8 Local entropy generations in the central plan for various Hartmann and Richardson numbers.
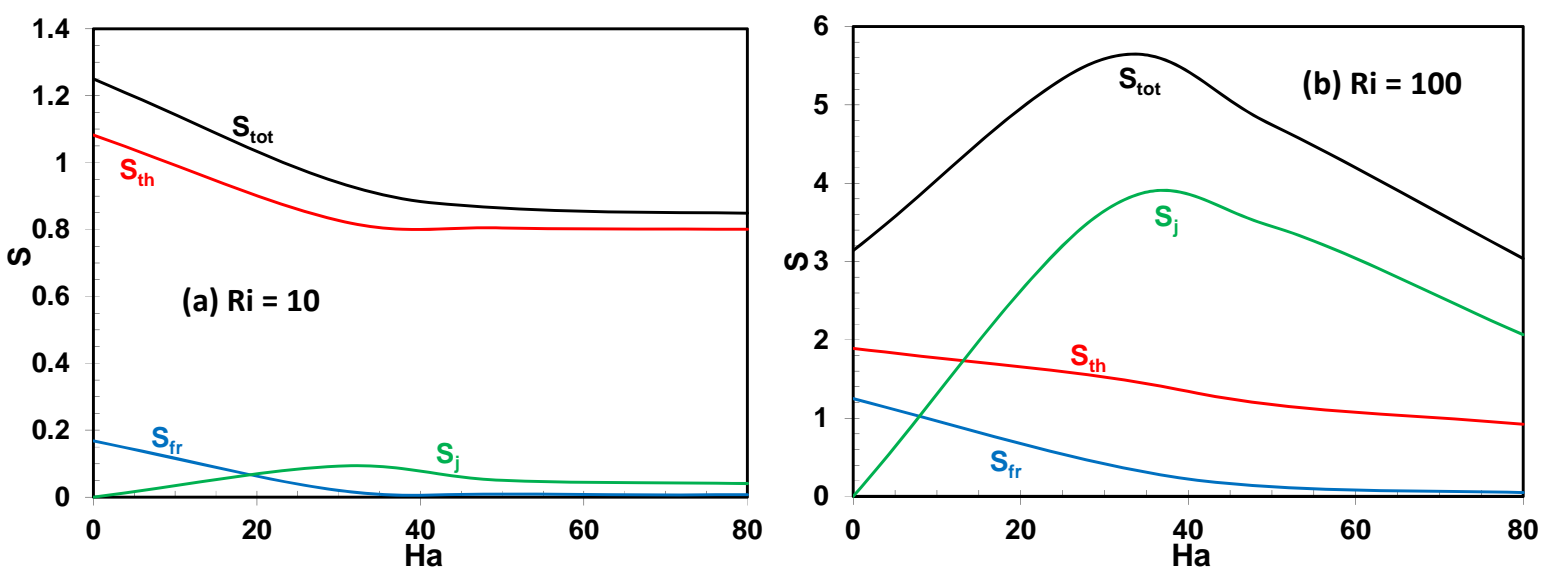

Fig.9 Entropy generations for various Hartmann and Richardson numbers.

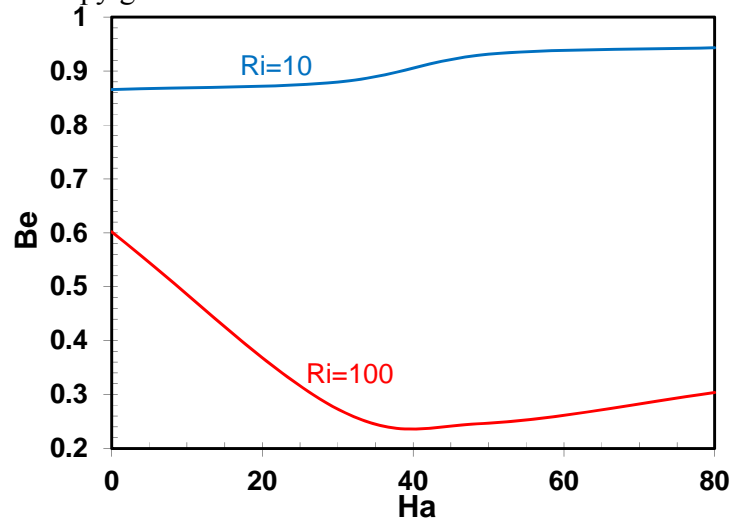

Fig.10 Variation of Bejan number for various values of Hartmann number. 


\begin{tabular}{|c|c|}
\hline $\mathrm{Nu}$ & Nusselt number \\
\hline$N_{s}$ & Local generated entropy \\
\hline$\vec{n}$ & Unit vector normal to the wall. \\
\hline $\operatorname{Pr}$ & Prandtl number \\
\hline$\vec{q}^{\prime}$ & Heat flux vector (W) \\
\hline $\mathrm{Ra}$ & Rayleigh number \\
\hline $\operatorname{Re}$ & Reynolds number \\
\hline $\mathrm{Ri}$ & Richardson number \\
\hline$S_{g e n}^{\prime}$ & Generated entropy \\
\hline $\mathrm{t}$ & Dimensionless time $\left(=t^{\prime} . \alpha / l^{2}\right)$ \\
\hline $\mathrm{T}$ & Dimensionless temperature $\left[=\left(T^{\prime}-T_{c}^{\prime}\right) /\left(T_{h}^{\prime}-T_{c}^{\prime}\right)\right]$ \\
\hline$T_{c}^{\prime}$ & Cold temperature $(\mathrm{K})$ \\
\hline$T_{h}^{\prime}$ & Hot temperature $(\mathrm{K})$ \\
\hline$T_{o}$ & Bulk temperature, $T_{o}=\left(T_{c}+T_{h}\right) / 2$ \\
\hline$\vec{V}$ & Dimensionless velocity vector $\left(=\vec{V}^{\prime} . l / \alpha\right)$ \\
\hline$x, y, z$ & Dimensionless Cartesian coordinates $\left(x^{\prime} / l, y^{\prime} / l, z^{\prime} / l\right)$ \\
\hline \multicolumn{2}{|c|}{ Greek symbols } \\
\hline$\alpha$ & Thermal diffusivity $\left(\mathrm{m}^{2} / \mathrm{s}\right)$ \\
\hline$\beta$ & Coefficient of thermal expansion $\left(\mathrm{K}^{-1}\right)$ \\
\hline$\rho$ & Density $\left(\mathrm{kg} / \mathrm{m}^{3}\right)$ \\
\hline$\rho_{e}$ & Density of electrical charge $\left(\mathrm{C} / \mathrm{m}^{3}\right)$ \\
\hline$\mu$ & Dynamic viscosity (kg /m.s) \\
\hline$v$ & Kinematics viscosity $\left(\mathrm{m}^{2} / \mathrm{s}\right)$ \\
\hline$v_{0}$ & Characteristic speed of fluid $(=\alpha / l)$ \\
\hline$\varphi$ & Irreversibility coefficient \\
\hline$\Phi$ & Dimensionless electrical potential \\
\hline$\phi^{\prime}$ & Dissipation function \\
\hline$\sigma_{\mathrm{e}}$ & Electrical conductivity (W / m. K ) \\
\hline$\vec{\psi}$ & Dimensionless vector potential $\left(\vec{\psi}^{\prime} / \alpha\right)$ \\
\hline$\vec{\omega}$ & Dimensionless vorticity $\left(=\vec{\omega}^{\prime} . \alpha / l^{2}\right)$ \\
\hline \multicolumn{2}{|c|}{ Subscripts } \\
\hline av & Average \\
\hline $\mathrm{x}, \mathrm{y}, \mathrm{z}$ & Cartesian coordinates \\
\hline fr & Friction \\
\hline $\mathrm{J}$ & Joule \\
\hline $\max$ & Maximum \\
\hline th & Thermal \\
\hline & Total \\
\hline & Dimensional variable \\
\hline
\end{tabular}

\section{REFERENCES}

Abidi A., Kolsi L., Borjini M.N., Ben Aissia H., 2011, "Effect of Radiative Heat Transfer on Three-Dimensional Double Diffusive Natural Convection," Numerical Heat Transfer, Part A: Applications 60 (9), 785-809, http://dx.doi.org/10.1080/10407782.2011.627797

Aich W., Kolsi L., Borjini M.N., Ben Aissia H., Oztop H.F., AbuHamdehd N., 2016, "Three Dimensional CFD Analysis of BuoyancyDriven Natural Ventilation and Entropy Generation in a Prismatic Greenhouse," Thermal science, (In Press). http://dx.doi.org/10.2298/tsci151015052a

Chamkha A., 2002, "Hydromagnetic Combined Convection Flow In a Vertical Lid-Driven Cavity With Internal Heat Generation or Absorption," Numerical Heat Transfer: Part A, 41, 529-546. http://dx.doi.org/10.1080/104077802753570356
Hussein A.K., Kolsi L., Chand R., Sivasankaran S., Fathinia F., Borjini M.N., Ben Aïssia H. , 2016, "Three-Dimensional Unsteady Natural Convection and Entropy Generation in an Inclined Cubical Trapezoidal Cavity Subjected to Uniformly Heated Bottom Wall," Alexandria Engineering Journal, 55, 741-755.

http://dx.doi.org/10.1016/j.aej.2016.01.004

Kolsi L., Abidi A., Borjini M., Daous N., Ben Aïssia H., 2007, "Effect of an External Magnetic Field on the 3-D Unsteady Natural Convection in A Cubical Enclosure" Numerical Heat Transfer, Part A, 51, 10031021. http://dx.doi.org/10.1080/10407790601184462

Kolsi L., Oztop H.F., Borjini M., Al-Salem K., 2011, "Second Law Analysis in a Three-Dimensional Lid-Driven Cavity," Int. Comm. in Heat Mass Transfer, 38, 1376-1383. http://dx.doi.org/10.1016/j.icheatmasstransfer.2011.08.019

Kolsi L., Hussein A.K., Borjini M.N., Mohammed H.A., Ben Aïssia H., 2014, "Computational Analysis of Three-Dimensional Unsteady Natural Convection and Entropy Generation in a Cubical Enclosure Filled with Water-A12O3 Nanofluid," Arabian Journal for Science and Engineering 39 (11), 7483-7493. http://dx.doi.org/10.1007/s13369-0141341-y

Kolsi L., Oztop H.F., Alghamdi A., Abu-Hamdeh N., Borjini M.N., Ben Aissia H., 2016, "A Computational Work on Three Dimensional Analysis of Natural Convection and Entropy Generation in Nanofluid Filled Enclosures with Triangular Solid Insert at the Corners," Journal of molecular liquids, 218, 260-274.

http://dx.doi.org/10.1016/j.molliq.2016.02.083

Kolsi L., Mahian O., Oztop H.F., Aich W., Borjini M.N, Abu-Hamdeh N., and Ben Aissia H., 2016, "3D Buoyancy Induced Flow and Entropy Generation of Nanofluid Filled Open Cavity Having Adiabatic Diamond Shaped Obstacle," ENTROPY, 18 (6) 232. http://dx.doi.org/10.3390/e18060232

Kolsi L., Kalidasan K., Alghamdi A., Borjini M.N., Kanna P.R., 2016, "Natural Convection and Entropy Generation on a Cubical Cavity with Twin Adiabatic Blocks and Filled by Aluminium Oxide - Water Nanofluid," Numerical Heat Transfer Part A, 70 (3), 242-259. http://dx.doi.org/10.1080/10407782.2016.1173478

Kolsi L., Oztop H.F., Abu-Hamdeh N., Alghamdi A., Borjini M.N., 2016, "Three Dimensional Analysis of Natural Convection and Entropy Generation in a Sharp Edged Finned Cavity" Alexandria Engineering Journal, 55, 991-1004. http://dx.doi.org/10.1016/j.aej.2016.02.030

Maatki C., Ghachem K. , Kolsi L., Hussein A.K., Borjini M.N., Ben Aissia H., 2016, "Inclination Effects of Magnetic Field Direction In 3D Double-Diffusive Natural Convection," Applied Mathematics and computation., 273, 178-189.

http://dx.doi.org/10.1016/i.amc.2015.09.043

Maatki C., Hassen W., Kolsi L., AlShammari N., Borjini M.N. and Ben Aissia H., 2016, "3D Numerical Study of Hydromagnetic Double Diffusive Natural Convection and Entropy Generation in Cubic Cavity," Journal of Applied Fluid Mechanics, 9 (4), 1915-1925.

Maatki C., Kolsi L., Oztop H.F., Chamkha A., Borjini M.N., Ben Aissia H., Al-Salem K., 2013, "Effects of Magnetic Field on 3D Double 
Diffusive Convection in a Cubic Cavity Filled with a Binary Mixture," International Communications in Heat and Mass Transfer 49, 86-95. http://dx.doi.org/10.1016/j.icheatmasstransfer.2013.08.019

Martyushev S.G, Sheremet M.A., 2014, "Conjugate Natural Convection Combined with Surface Thermal Radiation in a Three-Dimensional Enclosure with a Heat Source," Int. J. Heat and Mass Transfer 73, 340353. http://dx.doi.org/10.1016/j.ijheatmasstransfer.2014.02.009

Nasrin, R., 2010, "Mixed Magneto Convection in A Lid-Driven Cavity with a Sinusoidal Wavy Wall and a Central Heat Conducting Body," Journal of Naval Architecture and Marine Engineering, 7, 13-24. http://dx.doi.org/10.3329/jname.v8i1.6793

Nasrin R., Parvin S., 2011,"Hydromagnetic Effect on Mixed Convection in a Lid-Driven Cavity with Sinusoidal Corrugated Bottom Surface," Int. Comm. Heat Mass Transfer, 38, 781-789. http://dx.doi.org/10.1016/j.icheatmasstransfer.2011.03.002

Oztop H., Al-Salem K., Pop I., 2011, "MHD Mixed Convection in a Lid-Driven Cavity with Corner Heater," Int. J. Heat Mass Transfer, 54, 3494-3504. http://dx.doi.org/10.1016/j.ijheatmasstransfer.2011.03.036

Ozoe H., Okada K., 1989, "The Effect of the Direction of the External Magnetic Field on The Three-Dimensional Natural Convection in a Cubical Enclosure," Int. J. Heat Mass Transfer, 32, 1939-1954. http://dx.doi.org/10.1016/0017-9310(89)90163-4

Rahman M., Alim M., Chowdhury M., 2009, "Magnetohydrodynamic Mixed Convection Around a Heat Conducting Horizontal Circular
Cylinder in a Rectangular Lid-Driven Cavity with Joule Heating," J. Scientific Research, 1, 461-472. http://dx.doi.org/10.3329/jsr.v1i3.2597

Rahman M., Alim M., Sarker M., 2010, "Numerical Study on the Conjugate Effect of Joule Heating and Magneto-Hydrodynamics Mixed Convection in an Obstructed Lid-Driven Square Cavity," International Communications in Heat and Mass Transfer, 37, 524534.http://dx.doi.org/10.1016/j.proeng.2013.03.149

Rahman M., Billah M., Mamun M., Saidur R., Hassanuzzaman M., 2010, "Reynolds and Prandtl Numbers Effects on MHD Mixed Convection in a Lid-Driven Cavity Along with Joule Heating and a Centered Heat Conducting Circular Block," Int. J. Mechanical Materials Engineering, 5, 163-170.

Rahman M., Mamun M., Saidur R., 2011, “Analysis of MagnetoHydrodynamic Mixed Convection and Joule Heating in Lid-Driven Cavity Having a Square Block," Journal of the Chinese Institute of Engineers, 34, 585-599.

http://dx.doi.org/10.1080/02533839.2011.577591

Sheremet M.A., 2015, "Unsteady Conjugate Natural Convection in a Three-Dimensional Porous Enclosure," Numerical Heat Transfer A 68, 243-267. http://dx.doi.org/10.1080/10407782.2014.977172

Sivasankaran S., Malleswaran A., Lee J., Sundar P., 2011, "HydroMagnetic Combined Convection in a Lid-Driven Cavity with Sinusoidal Boundary Conditions on Both Sidewalls," Int. J. Heat Mass Transfer, 54, 512-525.

http://dx.doi.org/10.1016/j.ijheatmasstransfer.2010.09.018 